\title{
On the Isotope-Like Effect for High-T Superconductors in the Scenario of 2-Phonon Exchange Mechanism for Pairing
}

\author{
G. P. Malik ${ }^{1,2}$ \\ ${ }^{1}$ Present Address: B-208 Sushant Lok 1, Gurgaon, Haryana, India \\ ${ }^{2}$ Formerly: Theory Group, School of Environmental Sciences, Jawaharlal Nehru University, New Delhi, India \\ Email: gulshanpmalik@yahoo.com,malik@mail.jnu.ac.in
}

How to cite this paper: Malik, G.P. (2018) On the Isotope-Like Effect for High- $\mathrm{T}_{c}$ Superconductors in the Scenario of 2-Phonon Exchange Mechanism for Pairing. World Journal of Condensed Matter Physics, 8, 109-114.

https://doi.org/10.4236/wjcmp.2018.83007

Received: August 1, 2018

Accepted: August 21, 2018

Published: August 24, 2018

Copyright $\odot 2018$ by author and Scientific Research Publishing Inc. This work is licensed under the Creative Commons Attribution International License (CC BY 4.0).

http://creativecommons.org/licenses/by/4.0/

\begin{abstract}
By generalizing the isotope effect for elemental superconductors (SCs) to the case of pairing in the 2-phonon exchange mechanism for composite SCs, we give here an explanation of the well-known increase in the critical temperature $\left(\mathrm{T}_{\mathrm{c}}\right)$ of $\mathrm{Bi}_{2} \mathrm{Sr}_{2} \mathrm{CaCu}_{2} \mathrm{O}_{8}$ from $95 \mathrm{~K}$ to $110 \mathrm{~K}$ and of $\mathrm{Bi}_{2} \mathrm{Sr}_{2} \mathrm{Ca}_{2} \mathrm{Cu}_{3} \mathrm{O}_{10}$ from 105 to $115-125 \mathrm{~K}$ when $\mathrm{Bi}$ and $\mathrm{Sr}$ in these are replaced by $\mathrm{Tl}$ and $\mathrm{Ba}$, respectively. On this basis, we also give the estimated $\mathrm{T}_{c} \mathrm{~s}$ of some hypothetical SCs, assuming that they may be fabricated by substitutions similar to $\mathrm{Bi} \rightarrow \mathrm{Tl}$ and $\mathrm{Sr} \rightarrow \mathrm{Ba}$.
\end{abstract}

\section{Keywords}

Isotope-Like Effect, 2-Phonon Exchange Mechanism, Bi- and Tl-Based High- $\mathrm{T}_{c}$ SCs, Suggestions for New Substitutions for Further Enhancement of $\mathrm{T}_{\mathrm{c}}$ of the Bi-Based SCs

\section{Introduction}

In this note we deal with an explanation of why the replacements of $\mathrm{Bi}$ and $\mathrm{Sr}$ in $\mathrm{Bi}_{2} \mathrm{Sr}_{2} \mathrm{CaCu}_{2} \mathrm{O}_{8}$ and $\mathrm{Bi}_{2} \mathrm{Sr}_{2} \mathrm{Ca}_{2} \mathrm{Cu}_{3} \mathrm{O}_{10}$ by $\mathrm{Tl}$ and $\mathrm{Ba}$, respectively, lead to an increase in the critical temperature $\mathrm{T}_{\mathrm{c}}$ of the former from $95 \mathrm{~K}$ to $110 \mathrm{~K}$ and of the latter from 105 to $115-125 \mathrm{~K}$. This is an important undertaking because it has the potential to act as a general guide about substituting one or the other element in a composite superconductor (SC) in order to enhance its $\mathrm{T}_{c}$.

Empirically, it has been shown [1] that greater the $\mathrm{T}_{\mathrm{c}}$ of an SC, greater is its critical current density $j_{0}$, for which, theoretically, an expression has been derived in terms of the following five parameters [2] [3]: Debye temperature $\theta$, the 
electronic specific heat constant $\gamma$, gram-atomic volume $\mathrm{v}_{\mathrm{g}}$, Fermi energy $E_{F}$, and a dimensionless construct $y=\left(k \theta / P_{0}\right) \sqrt{2 m^{*} / E_{F}}$ where $k$ is the Boltzmann constant, $P_{0}$ the critical momentum of Cooper pairs and $m^{*}$ the effective mass of an electron. Therefore, if theory could predict the values of these parameters after one or more substitutions are made in an SC, then we would have a handle on its $\mathrm{j}_{0}$ and $T_{\mathrm{c}}$. Since, as of now, theory cannot perform this task, we must resort to an approach that relies on a property or properties that can be unequivocally determined, regardless of the number of elements that are replaced by others. Such a property is the mass of the SC.

Above considerations lead us to recall the isotope effect

$$
T_{c} \infty M^{-\alpha},
$$

where $M$ is the average mass of ions of an elemental SC. While BCS theory gives the value of $\alpha$ as 0.5 , values significantly different from this have also been found for some elements, e.g., Mo, Os, and $\mathrm{Ru}$, which are characterized by $\alpha=0.33$, 0.2 , and 0 , respectively. Hence, while (1) does not have the status of a law, it nonetheless helped in the formulation of BCS theory because it sheds light on the role of the ion lattice in the scenario of 1-phonon exchange mechanism (1 PEM) for pairing. Since the $T_{c} s$ and gaps of all the SCs dealt with here have been explained in the framework of the generalized-BCS equations (GBCSEs) employing the 2-phonon exchange mechanism (2 PEM) [4], we take up in the next Section the task of generalizing (1) for this case. Applications of the generalized equation are addressed in Section 3, where also given are the estimated values of $\mathrm{T}_{\mathrm{c}} \mathrm{s}$ of some members of the families of SCs represented by $\mathrm{X}_{2} \mathrm{Y}_{2} \mathrm{CaCu}_{2} \mathrm{O}_{8}$ and $\mathrm{X}_{2} \mathrm{Y}_{2} \mathrm{Ca}_{2} \mathrm{Cu}_{3} \mathrm{O}_{10}$ for different choices of $\mathrm{X}$ and $\mathrm{Y}$. The final Section sums up our present study.

\section{Isotope-Like Effect in the 2 PEM Scenario}

GBCSE for the $T_{c}$ of a composite SC in the $2 \mathrm{PEM}$ scenario is [5]

$$
\begin{aligned}
& \operatorname{Re}\left\{\frac{\lambda_{1}}{2} \int_{-k \theta_{1}}^{k \theta_{1}} d \xi \frac{\sqrt{\xi+\mu} \tanh \left(\xi / 2 k T_{c}\right)}{\xi}+\frac{\lambda_{2}}{2} \int_{-k \theta_{2}}^{k \theta_{2}} d \xi \frac{\sqrt{\xi+\mu} \tanh \left(\xi / 2 k T_{c}\right)}{\xi}\right\} \\
& =\operatorname{Re}\left\{\left[\frac{3}{4} \int_{-\mu}^{k \theta_{2}} d \xi \sqrt{\xi+\mu}\left\{1-\tanh \left(\xi / 2 k T_{c}\right)\right\}\right]^{1 / 3}\right\}
\end{aligned}
$$

where chemical potential $\mu$ has been used interchangeably with $E_{F} \theta_{1}$ and $\theta_{2}$ are the Debye temperatures and $\lambda_{1}$ and $\lambda_{2}$ the interaction parameters of the ion-species responsible for pairing, and the operator $R e$ ensures that the integrals yield real values even when $\xi+\mu<0$. When either of the $\lambda \mathrm{s}$ is zero and $\mu>\mathrm{k} \theta_{1}$ (or $\left.\mathrm{k} \theta_{2}\right),(2)$ reduces to the usual BCS equation for the $\mathrm{T}_{\mathrm{c}}$ of an elemental SC in the 1 PEM scenario. Since $T_{c}$ of an SC in the 2 PEM scenario is due to the cooperative effect of two kinds of ions, the following generalization of (1) suggests itself naturally

$$
T_{c}=p\left(M_{1} M_{2}\right)^{-\alpha}
$$


where $p$ is the constant of proportionality and $M_{1}$ and $M_{2}$ are the masses of the ion-species that cause pairing. A discussion of (3) vis-à-vis (1) will be given below.

\section{Applications of Equation (3)}

\section{1. $\mathrm{Bi}_{2} \mathrm{Sr}_{2} \mathrm{CaCu}_{2} \mathrm{O}_{8}$}

Pairing in this SC may be caused by the cooperative effect of one or more of the following pairs of ions: $\mathrm{Bi}$ and $\mathrm{Sr}, \mathrm{Bi}$ and $\mathrm{Ca}$, and $\mathrm{Sr}$ and $\mathrm{Ca}$. For each of these choices, guided by the values of $\alpha$ noted in Section 1, we calculate the value of $\mathrm{p}$ corresponding to $\mathrm{T}_{\mathrm{c}}=95 \mathrm{~K}$, and $\alpha=0.5,0.4,0.3,0.2$, and 0.1. With $\mathrm{M}_{\mathrm{Bi}}=208.98$, $\mathrm{M}_{\mathrm{Sr}}=87.62$, and $\mathrm{M}_{\mathrm{Ca}}=40.08(\mathrm{amu})$, we then obtain the results given in Table 1.

\section{2. $\mathrm{Tl}_{2} \mathrm{Ba}_{2} \mathrm{CaCu}_{2} \mathrm{O}_{8}$}

We calculate $\mathrm{T}_{\mathrm{c}}\left(\mathrm{Tl}_{2} \mathrm{Ba}_{2} \mathrm{CaCu}_{2} \mathrm{O}_{8}\right)$ via (3) for each of the $15\{\alpha, \mathrm{p}\}$-values in Table 1 by successively taking $M_{1} M_{2}$ as $M_{T 1} M_{B a}, M_{T 1} M_{C a}$, and $M_{B a} M_{C a}$. With $M_{T 1}=$ 204.39 and $\mathrm{M}_{\mathrm{Ba}}=137.33$ (amu), the resulting 45 values are given in Table 2 .

It is seen from Table 1 and Table 2 that while $\alpha=0.2$ and $\mathrm{p}=676.6$ correspond to $\mathrm{T}_{\mathrm{c}}\left(\mathrm{Bi}_{2} \mathrm{Sr}_{2} \mathrm{CaCu}_{2} \mathrm{O}_{8}\right)=95 \mathrm{~K}$ in the $2 \mathrm{PEM}$ scenario involving predominantly the $\mathrm{Bi}$ and $\mathrm{Sr}$ ions, they lead to $\mathrm{T}_{\mathrm{c}}\left(\mathrm{Tl}_{2} \mathrm{Ba}_{2} \mathrm{CaCu}_{2} \mathrm{O}_{8}\right)=111.6$. $\mathrm{K}$ when pairing is predominantly due to the $\mathrm{Tl}$ and $\mathrm{Ca}$ ions. Two other notable pairs of $\{\alpha$, p\}-values in Table 1 are $\{0.3,1427.7\}$ and $\{0.1,253.5\}$ which yield, respectively, values of $\mathrm{T}_{\mathrm{c}}\left(\mathrm{Tl}_{2} \mathrm{Ba}_{2} \mathrm{CaCu}_{2} \mathrm{O}_{8}\right)$ as 107.8 and $107.1 \mathrm{~K}$ (pairing via the $\mathrm{Ba}$ and $\mathrm{Ca}$ ions in each case); both of these $\mathrm{T}_{\mathrm{c}} \mathrm{s}$ are also close to the experimental values of $110 \mathrm{~K}$.

Since $\mathrm{Bi}$ and $\mathrm{Tl}$ belong to the same period and $\mathrm{Sr}$ and $\mathrm{Ba}$ to the same group of the periodic table, it seems interesting to investigate the effects of further similar substitutions in light of the above results. We assume that it is feasible to obtain the compounds noted below from the parent compound $\mathrm{Bi}_{2} \mathrm{Sr}_{2} \mathrm{CaCu}_{2} \mathrm{O}_{8}$.

For $\alpha=0.2$ and $\mathrm{p}=676.6 \mathrm{Kamu}^{2 \alpha}$, we obtain

1) $\mathrm{T}_{\mathrm{c}}\left(\mathrm{Bi}_{2} \mathrm{Mg}_{2} \mathrm{CaCu}_{2} \mathrm{O}_{8}\right)$; via $\left.\mathrm{Bi}+\mathrm{Mg}\right)=123 \mathrm{~K}=\mathrm{T}_{\mathrm{c}}\left(\mathrm{Tl}_{2} \mathrm{Mg}_{2} \mathrm{CaCu}_{2} \mathrm{O}_{8}\right)$; via $\mathrm{Tl}+$ $\mathrm{Mg})$

2) $\mathrm{T}_{\mathrm{c}}\left(\mathrm{Bi}_{2}\left(\right.\right.$ or $\left.\left.\mathrm{Tl}_{2}\right) \mathrm{Mg}_{2} \mathrm{CaCu}_{2} \mathrm{O}_{8}\right)$; via $\left.\mathrm{Bi}+\mathrm{Mg}\right)=171 \mathrm{~K}$

Table 1. The values of $\mathrm{p}$ obtained by solving (3) corresponding to $\mathrm{T}_{\mathrm{c}}=95 \mathrm{~K}, \alpha=0.5,0.4$, $0.3,0.2$, and 0.1 and different choices of ions responsible for pairing in $\mathrm{Bi}_{2} \mathrm{Sr}_{2} \mathrm{CaCu}_{2} \mathrm{O}_{8}$.

\begin{tabular}{cccc}
\hline$\alpha$ & $\begin{array}{r}\mathrm{p}(\mathrm{Bi}+\mathrm{Sr}) \\
\left(\mathrm{K} \mathrm{amu}{ }^{2 \alpha}\right)\end{array}$ & $\begin{array}{c}\mathrm{p}(\mathrm{Bi}+\mathrm{Ca}) \\
\left(\mathrm{K} \mathrm{amu}^{2 \alpha}\right)\end{array}$ & $\begin{array}{c}\mathrm{p}(\mathrm{Sr}+\mathrm{Ca}) \\
\left(\mathrm{Kamu}^{2 \alpha}\right)\end{array}$ \\
\hline 0.5 & 12855.2 & 8694.4 & 5629.7 \\
0.4 & 4817.3 & 3523.2 & 2488.5 \\
0.3 & 1805.2 & 1427.7 & 1100.0 \\
0.2 & 676.5 & 578.5 & 486.2 \\
0.1 & 253.5 & 234.4 & 214.9 \\
\hline
\end{tabular}


Table 2. $\mathrm{T}_{\mathrm{c}}\left(\mathrm{Tl}_{2} \mathrm{Ba}_{2} \mathrm{CaCu}_{2} \mathrm{O}_{8}\right)$ calculated via (3) for each pair of $\{\alpha, \mathrm{p}\}$ values in Table 1 for different combinations of ions in the 2 PEM scenario.

\begin{tabular}{|c|c|c|c|c|}
\hline$\alpha$ & $\mathrm{p}$ & $\begin{array}{c}\mathrm{T}_{\mathrm{c}}(\mathrm{Tl}+\mathrm{Ba}) \\
\mathrm{K}\end{array}$ & $\begin{array}{c}\mathrm{T}_{\mathrm{c}}(\mathrm{Tl}+\mathrm{Ca}) \\
\mathrm{K}\end{array}$ & $\begin{array}{c}\mathrm{T}_{\mathrm{c}}(\mathrm{Ba}+\mathrm{Ca}) \\
\mathrm{K}\end{array}$ \\
\hline \multirow[t]{3}{*}{0.5} & 12855.2 & 76.7 & 142.0 & 173.3 \\
\hline & 8694.4 & 51.9 & 96.1 & 117.2 \\
\hline & 5629.7 & 33.6 & 62.2 & 75.9 \\
\hline \multirow[t]{3}{*}{$\alpha=0.4$} & 4817.3 & 80.1 & 131.1 & 153.6 \\
\hline & 3523.2 & 58.6 & 95.8 & 112.4 \\
\hline & 2488.5 & 41.4 & 67.7 & 79.4 \\
\hline \multirow[t]{3}{*}{$\alpha=0.3$} & 1805.2 & 83.6 & 120.9 & 136.2 \\
\hline & 1427.7 & 66.1 & 95.6 & 107.8 \\
\hline & 1100.0 & 50.9 & 73.7 & 83.0 \\
\hline \multirow[t]{3}{*}{$\alpha=0.2$} & 676.5 & 87.2 & 111.6 & 120.8 \\
\hline & 578.5 & 74.6 & 95.4 & 103.3 \\
\hline & 486.2 & 62.7 & 62.7 & 86.8 \\
\hline \multirow[t]{3}{*}{$\alpha=0.1$} & 253.5 & 91.0 & 103.0 & 107.1 \\
\hline & 234.4 & 84.2 & 95.2 & 99.1 \\
\hline & 214.9 & 77.2 & 87.3 & 90.8 \\
\hline
\end{tabular}

3) $\mathrm{T}_{\mathrm{c}}\left(\mathrm{Bi}_{2} \mathrm{Be}_{2} \mathrm{CaCu}_{2} \mathrm{O}_{8}\right)$; via $\left.\mathrm{Bi}+\mathrm{Be}\right)=150 \mathrm{~K}=\mathrm{T}_{\mathrm{c}}\left(\mathrm{Tl}_{2} \mathrm{Be}_{2} \mathrm{CaCu}_{2} \mathrm{O}_{8}\right)$; via $\mathrm{Tl}+$ $\mathrm{Be})$

4) $\mathrm{T}_{\mathrm{c}}\left(\mathrm{Bi}_{2}\right.$ or $\left.\left(\mathrm{Tl}_{2}\right) \mathrm{Be}_{2} \mathrm{CaCu}_{2} \mathrm{O}_{8}\right)$; via $\left.\mathrm{Be}+\mathrm{Ca}\right)=208 \mathrm{~K}$

\section{3. $\mathrm{Bi}_{2} \mathrm{Sr}_{2} \mathrm{Ca}_{2} \mathrm{Cu}_{3} \mathrm{O}_{10}$ and $\mathrm{Tl}_{2} \mathrm{Ba}_{2} \mathrm{Ca}_{2} \mathrm{Cu}_{3} \mathrm{O}_{10}$}

Following the same procedure as above, we can find $15\{\alpha, \mathrm{p}\}$-values, each of them corresponding to $\mathrm{T}_{\mathrm{c}}\left(\mathrm{Bi}_{2} \mathrm{Sr}_{2} \mathrm{Ca}_{2} \mathrm{Cu}_{3} \mathrm{O}_{10}\right)=105 \mathrm{~K}$. Among these, the following four sets: $\{0.4,3894.1 ; \mathrm{Bi}+\mathrm{Ca}\},\{0.3,1578.0 ; \mathrm{Bi}+\mathrm{Ca}\},\{0.1,280.2 ; \mathrm{Bi}+\mathrm{Sr}\}$, and $\{0.2,747.7 ; \mathrm{Bi}+\mathrm{Sr}\}$ also lead to $\mathrm{T}_{\mathrm{c}}\left(\mathrm{Tl}_{2} \mathrm{Ba}_{2} \mathrm{Ca}_{2} \mathrm{Cu}_{3} \mathrm{O}_{10}\right)$ in the range $115-125$ $\mathrm{K}$; the $\mathrm{T}_{\mathrm{c}}$-values corresponding to the first three due to the $(\mathrm{Ba}+\mathrm{Ca})$ ions are $124.2,119.1$, and $118.4 \mathrm{~K}$, respectively, and the fourth value is $123.3 \mathrm{~K}$ due to the $(\mathrm{Tl}+\mathrm{Ca})$ ions.

Some typical $\mathrm{T}_{\mathrm{c}}$-values corresponding to $\{\alpha, \mathrm{p}\}=\{0.4,3894.1\}$ when $\mathrm{Sr}$ in $\mathrm{Bi}_{2} \mathrm{Sr}_{2} \mathrm{CaCu}_{3} \mathrm{O}_{10}$ is replaced by $\mathrm{Mg}$ and $\mathrm{Be}$, respectively, are 248.2 (due to $\mathrm{Mg}+$ $\mathrm{Ca}$ ) and $190.8 \mathrm{~K}$ (due to $\mathrm{Bi}+\mathrm{Be}$ ).

\section{Discussion and Conclusion}

It was noted above that BCS theory gives the value of $\alpha$ in (1) as 0.5 . This follows from two relations: (a) $k T_{c} \cong 1.13 \hbar \omega_{c} \exp (-1 /[N(0)] V)$, where $\omega_{c}$ is Debye frequency of the ions, $\mathrm{N}(0)$ the density of states at the Fermi surface, and $\mathrm{V}$ the net attraction between electrons bound as pairs, and (b) $\omega_{c} \infty M^{-1 / 2}$. It is hence 
seen that $\alpha=0.5$ only if $\mathrm{N}(0)$ and $\mathrm{V}$ do not change when one isotope is replaced by another. This is a reasonable assumption for $\mathrm{N}(0)$ because it is a purely electronic property; not so for $\mathrm{V}$ which is determined jointly by the ions and the electrons. It is not surprising therefore that $\alpha=0.5$ holds only for a few so-called classic elemental SCs, e.g., $\mathrm{Zn}, \mathrm{Pb}$, and $\mathrm{Hg}$ and that most of the other SCs are characterized by a multitude of values-some of which were noted above. Since, unlike elemental SCs, we do not have an analytic expression for the $\mathrm{T}_{c}$ of a composite SC, we cannot derive for it a "blanket relation" such as $\alpha=0.5$. The value of $\alpha$ for such SCs is expected to differ from family-to-family and we believe to have indicated how it may be tested; besides, in the best-case scenario, it may prove to be useful in the current endeavor to reach room temperature $T_{c} s$.

The applicability of the isotope effect via (1) has been investigated experimentally for the high- $\mathrm{T}_{c} \mathrm{SC} \mathrm{YBa}_{2} \mathrm{Cu}_{3} \mathrm{O}_{7}$ by replacing up to $75 \%$ of its $\mathrm{O}-16$ by O-18 [4]. Since this did not have any effect on the $\mathrm{T}_{c}$, it was concluded that $\alpha=0$ for this SC. We note in this context that scattering with the $\mathrm{O}$ ions is not the direct cause of pairing in any SC; what needs to be monitored is the change in $\mathrm{T}_{c}$ when one or more ions that are actually responsible for pairing are substituted. A remark about the vital role of $\mathrm{CuO}_{2}$ planes in an SC is in order since greater their number, greater is the $\mathrm{T}_{\mathrm{c}}$ of the SC. We believe that the dual role of these planes is (a) to meet the stoichiometric requirements for the stability of the SC when new ion layers are added to it to provide additional channels for pairing and (b) to provide additional sites for pairs to reside on.

To conclude, by appealing to an isotope-like effect, we have given here an explanation of the known increase in the $\mathrm{T}_{c} \mathrm{~s}$ of $\mathrm{Bi}_{2} \mathrm{Sr}_{2} \mathrm{CaCu}_{2} \mathrm{O}_{8}$ and $\mathrm{Bi}_{2} \mathrm{Sr}_{2} \mathrm{Ca}_{2} \mathrm{Cu}_{3} \mathrm{O}_{10}$ when $\mathrm{Bi}$ and $\mathrm{Sr}$ in these are replaced by $\mathrm{Tl}$ and $\mathrm{Ba}$, respectively. Based on this approach, we have given plausible values of $\mathrm{T}_{c} s$ of some hypothetical SCs that may be obtained from the parent SCs by one or more substitutions. Fabrication of these hypothetical SCs, e.g., $\mathrm{Tl}_{2} \mathrm{Be}_{2} \mathrm{CaCu}_{2} \mathrm{O}_{8}$ and ensuring that pairing in it occurs predominantly via the $\mathrm{Be}$ and the Ca ions (which lead to $\mathrm{T}_{\mathrm{c}}=208 \mathrm{~K}$ ), is a problem that belongs to the realm of chemical engineering.

\section{Acknowledgements}

Author thanks Professor D. C Mattis for a critical reading of the manuscript and for encouragement.

\section{References}

[1] Semenov, A., et al. (2009) Optical and Transport Properties of Ultrathin NbN and Nanostructures. Physical Review B, 80, 054510. https://doi.org/10.1103/PhysRevB.80.054510

[2] Malik, G.P. (2016) On the Role of Fermi Energy in Determining Properties of Superconductors: A Detailed Comparative Study of Two Elemental Superconductors (Sn and $\mathrm{Pb}$ ), a Non-Cuprate $\left(\mathrm{MgB}_{2}\right)$ and Three Cuptates (YBCO, Bi-2212 and Tl-2212). Journal of Superconductivity and Novel Magnetism, 29, 2755-2764. https://doi.org/10.1007/s10948-016-3637-5 
[3] Malik, G.P. (2018) Correction to: On the Role of Fermi Energy in Determining Properties of Superconductors: A Detailed Comparative Study of Two Elemental Superconductors $(\mathrm{Sn}$ and $\mathrm{Pb})$, a Non-Cuprate $\left(\mathrm{MgB}_{2}\right)$ and Three Cuptates (YBCO, Bi-2212 and Tl-2212). Journal of Superconductivity and Novel Magnetism, 31, 941-941. https://doi.org/10.1007/s10948-017-4520-8

[4] Malik, G.P. (2016) Superconductivity: A New Approach Based on the Bethe-Salpeter Equation in the Mean-Field Approximation. In: Directions in Condensed Matter Physics, Vol. 21, World Scientific, Singapore. https://doi.org/10.1142/9868

[5] Malik, G.P. (2018) On the $\mathrm{s}^{ \pm}$-Wave Superconductivity in the Iron-Based Superconductors: A Perspective Based on a Detailed Study of $\mathrm{Ba}_{0.6} \mathrm{~K}_{0.4} \mathrm{Fe}_{2} \mathrm{AS}_{2}$ via the Generalized-Bardeen-Cooper-Schrieffer Equations Incorporating Fermi Energy. Open Journal of Composite Materials, 7, 130-145.

https://doi.org/10.4236/ojcm2017.73008 